\title{
$Q$ fever: baseline monitoring of a sheep and a goat flock associated with human infections
}

\author{
R. EIBACH ${ }^{1 *}$, F. BOTHE ${ }^{1}$, M. RUNGE ${ }^{2}$, S. F. FISCHER ${ }^{3}$, W. PHILIPP 4 \\ AND M. GANTER ${ }^{1}$ \\ ${ }^{1}$ University of Veterinary Medicine Hannover, Foundation, Germany \\ ${ }^{2}$ Lower Saxony State Office for Consumer Protection and Food Safety, Veterinary Institute Hannover, Germany \\ ${ }^{3}$ Baden-Württemberg State Health Office, Stuttgart, Germany \\ ${ }^{4}$ University of Hohenheim, Germany
}

(Accepted 7 December 2011; first published online 5 January 2012)

\section{SUMMARY}

Animal losses due to abortion and weak offspring during a lambing period amounted up to $25 \%$ in a goat flock and up to $18 \%$ in a sheep flock kept at an experimental station on the Swabian Alb, Germany. Fifteen out of 23 employees and residents on the farm tested positive for Coxiella burnetii antibodies by enzyme-linked immunosorbent assay (ELISA) and indirect immunofluorescence assay. Ninety-four per cent of the goats and $47 \%$ of the sheep were seropositive for C. burnetii by ELISA. Blood samples of $8 \%$ of goats and $3 \%$ of sheep were PCR positive. C. burnetii was shed by all tested animals through vaginal mucus, by $97 \%$ of the goats and $78 \%$ of the sheep through milk, and by all investigated sheep through faeces (PCR testing). In this outbreak human and animal infection were temporally related suggesting that one was caused by the other.

Key words: Coxiella burnetii, Germany, outbreak, Q fever, shedding.

\section{INTRODUCTION}

Q fever is a zoonosis caused by the Gram-negative, obligate intracellular bacterium Coxiella burnetii. The disease has been known since the 1930s and occurs worldwide, except Antarctica and possibly New Zealand [1-3]. Q fever is a notifiable disease in only a few countries including Germany. The diagnosis is often overlooked due to its non-specific presentation in both humans and animals. As a result the true worldwide incidence is not known.

C. burnetii appears in three different morphological forms: large cell variants (LCV), small cell variants

\footnotetext{
* Author for correspondence: R. Eibach, Clinic for Swine and Small Ruminants, University of Veterinary Medicine, Hannover, Bischofsholer Damm 15, D-30173 Hannover, Germany.

(Email: Regina.Eibach@tiho-hannover.de)
}

(SCV), and small dense cells (SDC), which can be differentiated by their morphology, physical and chemical resistance as well as antigenic and metabolic characteristics $[4,5]$. The SDC and the SCV in particular are considered to be the persistent forms in the host [4] and are responsible for the high resistance of C. burnetii to environmental stress. They possess high levels of resistance to UV radiation, heat, desiccation, sonication, and pressure as well as osmotic and oxidative stress. Due to these facts these bacteria are able to survive extracellularly as infectious particles for at least 150 days $[4,6]$.

Furthermore, C. burnetii displays antigenic variation by appearing in two different infectious forms, phase I and a less infectious phase II [7]. This variation is related to changes in the lipopolysaccharide (LPS) layer [8-10]. Bacteria with a complete LPS

The online version of this article is published within an Open Access environment subject to the conditions of the Creative Commons Attribution-NonCommercial-ShareAlike licence $<$ http://creativecommons.org/licenses/by-nc-sa/2.5/ $>$. The written permission of Cambridge University Press must be obtained for commercial re-use. 
(phase I LPS), are highly virulent, whereas bacteria with phase II LPS have an atrophied LPS and show lower virulence $[9,11]$. C. burnetii infects several host species such as arthropods, birds, pets, domestic and wild mammals and humans [12], but ruminant livestock such as cattle, and in particular goats and sheep are identified as the most common sources of human infections [13, 14].

C. burnetii infections in goats and sheep are usually asymptomatic during the non-lambing period. The most common clinical manifestations appear during late pregnancy until lambing, i.e. abortion, stillbirth, and the delivery of weak offspring $[15,16]$. Other symptoms such as pneumonia, conjunctivitis and hepatitis occur rarely in infected animals [17]. Infected female animals shed large quantities of bacteria into the environment in the course of abortion or normal delivery, not only through the birth fluids, placenta, and fetal membranes, but also urine and faeces [17-19].

Inhaling aerosols, which have been contaminated with these parturition products or urine and faeces of infected animals, respectively, is the most important route of human $C$. burnetii infections [13, 15]. C. burnetii can also be transmitted, less commonly, through the consumption of raw milk and dairy products $[15,20]$. The diagnosis of acute $\mathrm{Q}$ fever in humans is frequently not made due to the non-specific nature of the illness. Features include fever, pneumonia, headache, and weakness. Chronic infection in humans can result in severe valvular endocarditis, granulomatous hepatitis, and rarely in osteomyelitis [17, 21].

Within the framework of a national $Q$ fever research project, experiments were performed at the Research Station for Animal Husbandry, Animal Breeding and Small Animal Breeding, University of Hohenheim on the Swabian Alb. The research station consists of two farms, Lower Lindenhof, where pigs, cattle, and poultry are kept, at an altitude of $489 \mathrm{~m}$, about $1 \mathrm{~km}$ away from the next village, and Upper Lindenhof about $2 \mathrm{~km}$ from Lower Lindenhof. Upper Lindenhof is situated in a solitary location on a plateau $720 \mathrm{~m}$ above sea level surrounded mainly by forest with the next village about $3 \mathrm{~km}$ away.

On this farm only goats and sheep are kept and a small number of houses and flats are let to employees and other residents.

In April 2009 the abortion rate in goats and sheep increased at Upper Lindenhof. The Chemical and
Veterinary Investigation Office (CVUA) in Stuttgart conducted pathological examinations on three aborted kid foetuses and parts of one placenta confirming infection with C. burnetii in April 2009. Four people, living or working on the farm, were also diagnosed with Q fever infections in March, May and June 2009. They presented with non-specific clinical symptoms such as raised temperature, fatigue, headache, muscle pain and breast pain. In three cases Q fever was diagnosed by the family doctor, based on serological investigations. In the other case polymerase chain reaction (PCR) from a laryngeal lavage confirmed the suspicion.

In May 2009, all animals of the research station were examined for $C$. burnetii infection using enzymelinked immunosorbent assay (ELISA) and PCR. ELISA and indirect immunofluorescence assay (IIFA) testing was performed on humans working or living on the farm in July 2010. Due to the isolated location of Upper Lindenhof this outbreak provided an opportunity to investigate vertical and horizontal transmission routes within sheep in the following lambing seasons and to follow-up the infectious situation of the flock until the end of 2012.

\section{METHODS}

Examinations were performed on 263 Merino land sheep and 165 Dahlem Cashmere goats (a triple purpose breed) as well as eight farm employees and 15 farm residents. Sheep and goats were kept separately in different barns, but grazed on the same pastures and were handled by the same shepherds. Delivery of 222 ewes occurred during February and March 2009, and of 72 goats during April and May 2009 with a further eight ewes during June and July 2009. Four of the infected employees were shepherds with direct contact with the animals. The other four infected employees were plant breeders, but they worked in close proximity to the animals as their premises and the fields were located between the different stables and pastures (Fig. 1). The residents' houses were located in the immediate vicinity of one of the three stables and some range land (Fig. 1).

\section{Ethics statement}

The experimental procedures on the animals were performed in accordance with the principles outlined by the European Convention for the Protection of Vertebrate Animals Used for Experimental and 


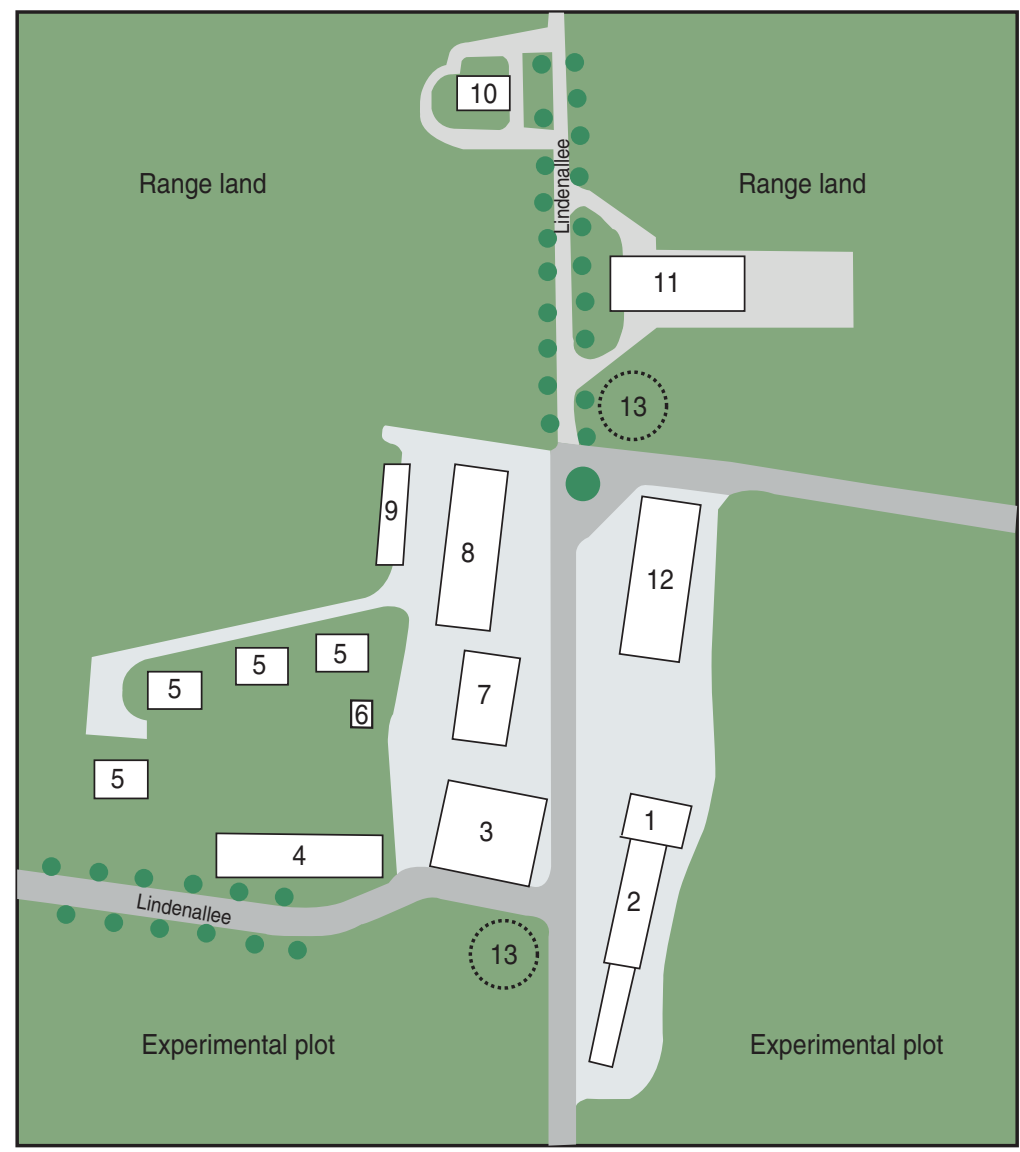

Fig. 1. Map of Upper Lindenhof. 1, Administration; 2, dairy goats barn and kid barn; 3, storage room; 4, laboratory - plant breeding; 5, residents' houses; 6, transformer station; 7, factory; 8, goat barn; 9, garages; 10, silo; 11, sheep barn; 12 , machinery hall; 13, underground water tank.

Other Scientific Purposes. Sampling of the animals was performed by veterinarians of the University of Veterinary Medicine Hannover Foundation. Human blood samples were obtained within the framework of occupational investigations concerning the $\mathrm{Q}$ fever outbreak and taken by the Company Medical Office of the University of Hohenheim.

\section{Samples}

\section{Goats and sheep}

In May 2009, serum samples were obtained from 261 sheep and 146 goats. The animals were bled by venepuncture of the vena cava cranialis [22], the blood was centrifuged $(10000 \mathrm{~g})$, and the supernatant was stored at $4{ }^{\circ} \mathrm{C}$.

Additionally, EDTA blood samples were acquired from 261 sheep and 142 goats. Vaginal swabs were taken from five ewes and 100 goats. Milk samples were taken from all nine ewes that were still lactating, and 64 goats. Before taking the milk samples, the udders were disinfected with a cloth moistened with alcohol (Desco Wipes, Dr. Schumacher GmbH, Germany). Rectal swabs were taken from nine sheep. The EDTA blood and milk samples, as well as the vaginal and rectal swabs were stored at $4{ }^{\circ} \mathrm{C}$ and analysed within $24 \mathrm{~h}$.

\section{Humans}

In July 2010, the 23 employees and residents had serum samples taken and completed a questionnaire compiled to obtain relevant information regarding age, gender, occupation, contact with the animals, pre-existing diseases, clinical symptoms, risk factors for $\mathrm{Q}$ fever, medical consultations and treatments.

\section{PCR}

\section{Goats and sheep}

DNA was extracted from swabs and milk samples with the Qiagen Mini kit (Qiagen, Germany) and the Nucleospin Tissue kit (Macherey-Nagel, Germany) 
according to the manufacturers' instructions. DNA extraction and PCR analyses of blood samples was performed temporally and spatially separated from milk samples and swabs with the Nucleospin Virus kit (Macherey-Nagel) using a Hamilton MicrolabStar robot (Hamilton, Germany).

The PCR for detecting C. burnetii was based on the method originally described by Willems et al. [23], which amplifies a 687-bp sequence of the IS1111 gene. In our investigations we used the LightCycler 2.0TM instrument (Roche Diagnostics, Germany). After the initial denaturation at $95^{\circ} \mathrm{C}$ for $10 \mathrm{~min}, 5$ cycles were performed with denaturation at $95^{\circ} \mathrm{C}$ for $4 \mathrm{~s}$, primer annealing at $75,73,71,69$ and $67^{\circ} \mathrm{C}$ for $8 \mathrm{~s}$ each and elongation at $77^{\circ} \mathrm{C}$ for $15 \mathrm{~s}$. After this 'touch-down' 35 cycles were run, denaturating at $95^{\circ} \mathrm{C}$ for $4 \mathrm{~s}$, annealing at $65^{\circ} \mathrm{C}$ for $8 \mathrm{~s}$, and elongating at $72{ }^{\circ} \mathrm{C}$ for $15 \mathrm{~s}$. Amplification of specific DNA fragments resulted in a product with an average $T_{\mathrm{m}}$ of $87.8^{\circ} \mathrm{C}$ (range $87 \cdot 7-88 \cdot 4{ }^{\circ} \mathrm{C}$ ). Negative controls to identify DNA carry-over and positive controls were included in each PCR run. Blood and tissue samples from uninfected sheep, which were negative in $C$. burnetii PCR in former investigations, were included in the DNA extraction procedure as negative controls and distilled water used as a no-template control. Placenta samples from a sheep infected with $C$. burnetii were used as a positive control.

\section{ELISA and IIFA}

\section{Goats and sheep}

Serum samples were analysed for the occurrence of antibodies against mixed phase I and phase II antigens of $C$. burnetii with a commercial ELISA (CHEKIT Q fever, IDEXX Laboratories, Germany) according to the manufacturer's instructions. The optical density (OD) of the positive control and the OD of the samples were corrected by subtracting the OD of the negative control. As recommended by the manufacturer, serum samples were considered to be positive by ELISA if they had a corrected OD value with a percentage of $\geqslant 40 \%$. They were considered negative if the percentage was $<30 \%$, and doubtful if it was between $30 \%$ and $40 \%$ compared to the positive control serum.

\section{Humans}

ELISA (Virion/Serion, Germany) was used as a screening test to detect $C$. burnetii antibodies (phase II $\mathrm{IgG}$, phase II IgM) in human serum samples in accordance with the manufacturer's instructions. Seropositive samples were confirmed by an investigation with an IIFA, detecting phase II IgG and phase II IgM as well as phase I IgG and phase I IgM (Bios, Focus Diagnostics, USA). The sera were tested in different dilutions $(1: 16,1: 32,1: 64,1: 128,1: 256$, $1: 512,1: 1024)$. A titre $\geqslant 1: 16$ for the $\operatorname{IgM}$ and $\operatorname{IgG}$ response to phase II was considered as a diagnostic titre for $\mathrm{Q}$ fever.

\section{RESULTS}

\section{Goats and sheep}

\section{Clinical signs}

In February and March 2009, an abnormally high number (eight) of abortions in sheep in the late pregnancy stage was observed at Upper Lindenhof. At first this incident was associated with a sheep-shearing workshop which had taken place on the farm in January. No further investigations were made at this stage, even though an increase in the number of weak offspring of up to $16 \%$ was also observed.

In April 2009, eight abortions in the late pregnancy stage in goats and a high number of weak offspring $(11 \%)$ within the goat flock prompted further investigation. C. burnetii infection was diagnosed in the aborted kid foetuses and a goat's placenta by CVUA.

During this season losses for goats amounted up to $25 \%$ (abortions, weak offspring) (Fig. 2); $14 \%$ losses were due to abortions and an additional $11 \%$ of offspring died within the first week due to weakness. In sheep the loss rate was up to $18 \% ; 2 \%$ losses due to abortions and $16 \%$ losses due to weak offspring. Five percent of the lambs died within the first week and $11 \%$ between the second and tenth week postnatal. No other clinical signs were observed within the sheep and goat flocks.

\section{Serological response}

Antibodies against $C$. burnetii were detected by an ELISA in $123 / 261$ sheep $(47 \%)$ and $137 / 146$ goats (94\%). C. burnetii-specific DNA sequences were detected in $7 / 261$ sheep blood samples $(3 \%)$ and in 12/142 goat blood samples ( $8 \%$ ) by PCR (Fig. 3). All vaginal swabs investigated (five sheep, 100 goats) were positive in the C. burnetii PCR (Fig. 3). Three of these sheep and 82 of these goats were also serologically positive (Table 1). All nine faecal swabs from sheep were positive. C. burnetii could be detected in $62 / 64$ $(97 \%)$ goat milk samples as well as in $7 / 9(78 \%)$ 


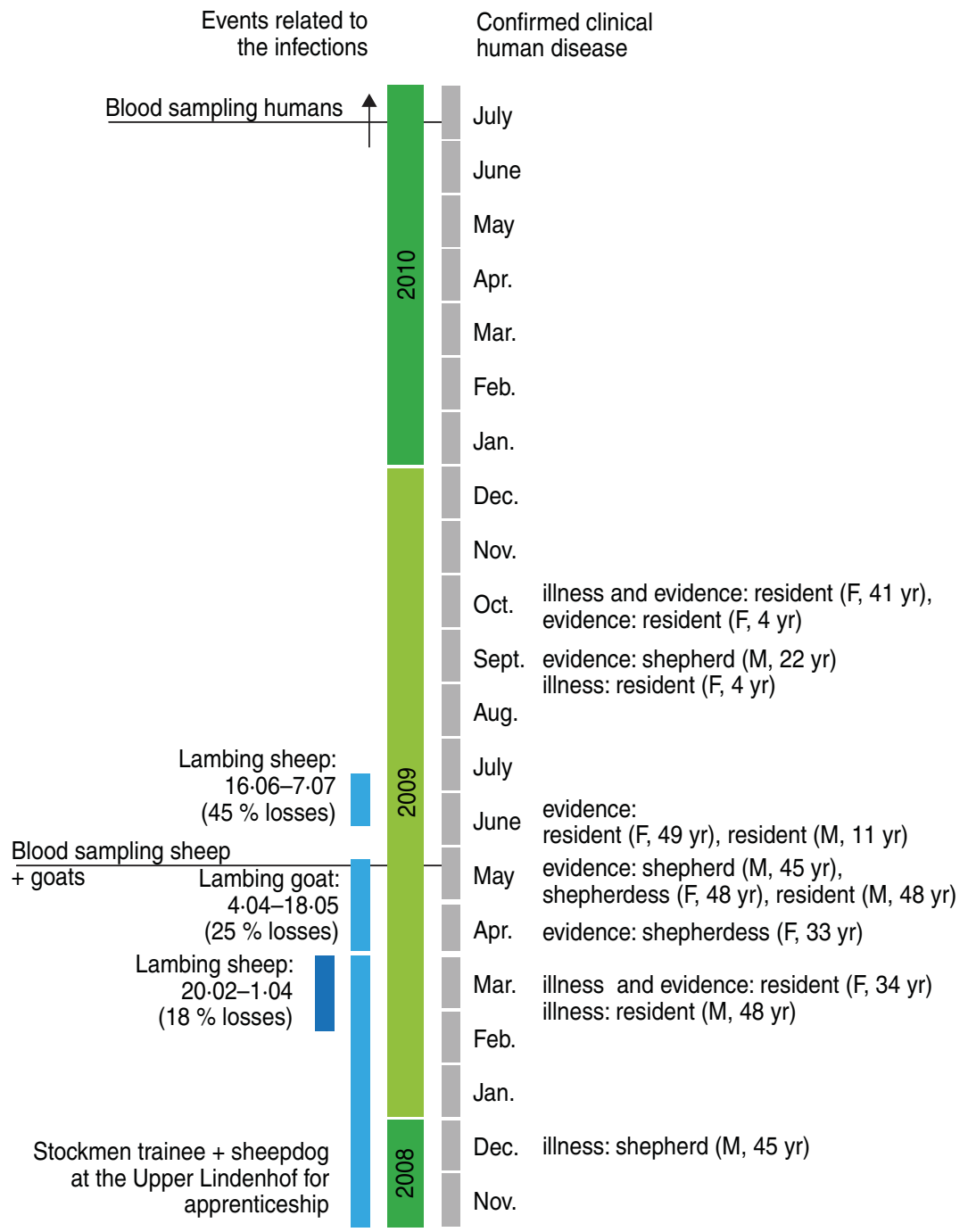

Fig. 2. Time scale 2008-2010.

sheep milk samples (Fig. 3). Table 1 shows the evaluation of the different sampling types in relation to the serum sample results.

\section{Humans}

\section{Serology}

Serological ELISA tests were performed in July 2010. All four stockmen, 2/4 of the plant breeders and 9/15 residents $(60 \%)$ tested positive (Fig. 4). In total 15/23 humans were seropositive by ELISA and IIFA. There were no differences in age or gender distribution of the positive individuals (Table 2). All human cases had IgM antibody in low concentrations and phase I IgG antibodies with titres between $1: 16$ and $1: 1024$. Phase II $\mathrm{IgG}$ antibodies were present (between 1:64 and $1: 1024$ ) in all but one resident (age 50 years, male; $14 / 15$ cases).

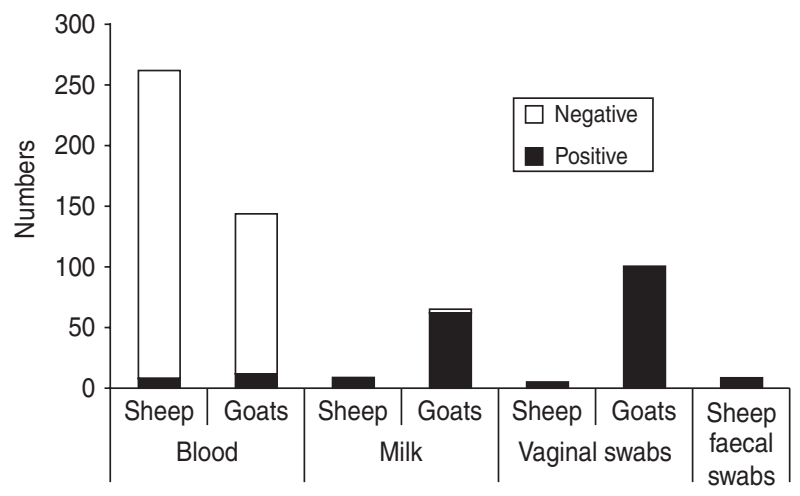

Fig. 3. PCR results of blood, milk, vaginal and faecal swabs of sheep and goats of Upper Lindenhof in May 2009.

\section{Clinical signs in humans}

Four residents reported clinical signs including severe headache, high temperature, fatigue, and muscle pain. 
Table 1. Evaluation of the PCR results in different sampling types in relation to the serological results

\begin{tabular}{|c|c|c|c|c|c|}
\hline \multirow[b]{2}{*}{ Sample } & \multicolumn{4}{|c|}{ Serum antibodies } & \multirow[b]{2}{*}{ Total } \\
\hline & PCR positive & PCR negative & PCR positive & PCR negative & \\
\hline Goats & (137 positive) & & (9 negative) & & 146 \\
\hline EDTA blood & 12 & 121 & 0 & 9 & 142 \\
\hline Milk & 53 & 3 & 2 & 0 & 58 \\
\hline Vaginal swabs & 82 & 0 & 3 & 0 & 85 \\
\hline Sheep & (123 positive) & & (138 negative) & & 261 \\
\hline EDTA blood & 4 & 121 & 2 & 134 & 261 \\
\hline Milk & 6 & 0 & 3 & 0 & 9 \\
\hline Vaginal swabs & 3 & 0 & 2 & 0 & 5 \\
\hline Faecal swabs & 7 & 0 & 2 & 0 & 9 \\
\hline
\end{tabular}

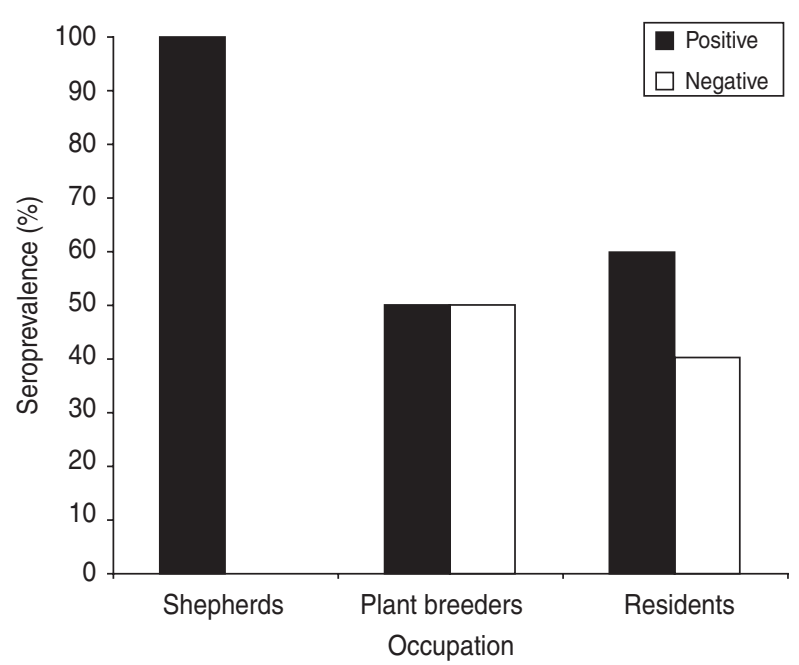

Fig. 4. Seroprevalence (IgG ELISA) within the three human groups living or working at Upper Lindenhof.

Two residents had already been diseased in March 2009, the other two in September and October 2009, respectively (Fig. 2). Three of these residents had been diagnosed with $\mathrm{Q}$ fever by their family doctor based on clinical signs and serological results (no details available). The fourth patient had to be admitted to hospital because of severe pneumonia in March 2009. In May 2009 his laryngeal lavage was positive by PCR for $C$. burnetii. Unfortunately, he did not take part in the blood examinations in July 2010 and therefore no serological data are available.

The four stockmen on the farm were diagnosed by their family doctors after $Q$ fever was recognized in the flocks. Only one of them showed any clinical symptoms typical for Q fever, i.e. severe headache, fatigue, muscle pain and chest pain, in December 2008 (Fig. 2).

In June 2009 two residents consulted their family doctor for other matters and were found incidentally to have antibodies to $\mathrm{Q}$ fever. The other ten residents and the four plant breeders did not know their serological status until our investigations took place in July 2010. In the serum samples of four residents and two plant breeders, antibodies against $C$. burnetii were found, but they could not remember any clinical symptoms within the previous 2 years (Table 2).

\section{DISCUSSION}

This case study describes the situation on an animal farm where an outbreak of $Q$ fever occurred in humans which was temporally related to infection of a goat and sheep flock at an isolated site.

Animal losses within the sheep and goat flock were more frequently due to weak offspring than abortions in this outbreak. In general, in a Q fever-positive flock of small ruminants the abortion rate can vary from $3 \%$ to $80 \%[4,16]$. Q fever should therefore be considered as a potential aetiological agent in flocks with increased losses due to weak offspring, regardless of the frequency of abortions.

In this study goats were more severely affected as they suffered more abortions and delivered more weak offspring than sheep. This study also shows that animals (particularly sheep) can carry and shed C. burnetii, without displaying significant clinical signs of illness [17]. According to our results, goats as well as sheep shed C. burnetii in their vaginal mucus, milk or faeces. This fact corroborates earlier studies where infected dairy animals shed a high number of C. burnetii not only with the products of conception $[18,24]$, but also with urine, faeces, and milk, for up to several months after parturition [19, 25]. The study demonstrates that during an acute outbreak of $\mathrm{Q}$ fever bacteria were excreted through all possible 
Table 2. First evidence of Q fever, evaluation and symptoms as well as age, gender and occupation-distribution of people living or working at Upper Lindenhof and serum titres of the C. burnetii-positive individuals in July 2010

\begin{tabular}{|c|c|c|c|c|c|c|c|c|c|c|}
\hline Occupation & Gender & $\begin{array}{l}\text { Age } \\
(\mathrm{yr})\end{array}$ & Symptoms & AT & First evidence & $\begin{array}{l}\text { ELISA } \\
\text { (July 2010) }\end{array}$ & $\begin{array}{l}\text { Phase I } \\
\text { IgG IIFA }\end{array}$ & $\begin{array}{l}\text { Phase II } \\
\text { IgG IIFA }\end{array}$ & $\begin{array}{l}\text { Phase I } \\
\text { IgM IIFA }\end{array}$ & $\begin{array}{l}\text { Phase II } \\
\text { IgM IIFA }\end{array}$ \\
\hline Plant breeder & M & 43 & - & & July 2010 , our investigations & - & & & & \\
\hline Plant breeder & $\mathrm{F}$ & 50 & - & & July 2010 , our investigations & - & & & & \\
\hline Plant breeder & M & 50 & - & & July 2010 , our investigations & + & $1: 128$ & $1: 1024$ & $1: 16$ & $1: 16$ \\
\hline Plant breeder & M & 57 & - & & July 2010 , our investigations & + & $1: 64$ & $1: 128$ & $1: 16$ & $1: 16$ \\
\hline Resident & $\mathrm{F}$ & 8 & - & & July 2010 , our investigations & - & & & & \\
\hline Resident & M & 39 & - & & July 2010 , our investigations & - & & & & \\
\hline Resident & $\mathrm{F}$ & 13 & - & & July 2010 , our investigations & - & & & & \\
\hline Resident & $\mathrm{F}$ & 42 & - & & July 2010 , our investigations & - & & & & \\
\hline Resident & M & 7 & - & & July 2010 , our investigations & - & & & & \\
\hline Resident & M & 46 & - & & July 2010 , our investigations & - & & & & \\
\hline Resident & $\mathrm{F}$ & 47 & - & & July 2010 , our investigations & + & $1: 64$ & $1: 256$ & $1: 16$ & $1: 32$ \\
\hline Resident & M & 41 & - & & July 2010 , our investigations & + & $1: 32$ & $1: 64$ & $1: 16$ & $1: 16$ \\
\hline Resident & M & 50 & - & & July 2010 , our investigations & + & $1: 16$ & $1: 32$ & $1: 16$ & $1: 64$ \\
\hline Resident & M & 15 & - & & July 2010 , our investigations & + & $1: 64$ & $1: 512$ & $1: 16$ & $1: 64$ \\
\hline Resident & M & 48 & $+03 / 2009$ & + & May 2009, PCR laryngeal lavage & & & & & \\
\hline Resident & M & 11 & - & & $\begin{array}{l}\text { June } 2009 \text {, family doctor, } \\
\text { incidental finding }\end{array}$ & + & $1: 128$ & $1: 512$ & $1: 16$ & $1: 16$ \\
\hline Resident & $\mathrm{F}$ & 49 & - & & $\begin{array}{l}\text { June } 2009 \text {, family doctor, } \\
\text { incidental finding }\end{array}$ & + & $1: 256$ & $1: 1024$ & $1: 16$ & $1: 16$ \\
\hline Resident & $\mathrm{F}$ & 34 & $+03 / 2009$ & + & March 2009, family doctor & + & $1: 16$ & $1: 512$ & $1: 16$ & $1: 16$ \\
\hline Resident & $\mathrm{F}$ & 41 & $+10 / 2009$ & + & October 2009 , family doctor & + & $1: 64$ & $1: 512$ & $1: 64$ & $1: 32$ \\
\hline Resident & $\mathrm{F}$ & 4 & $+09 / 2009$ & + & October 2009 , family doctor & + & $1: 512$ & $1: 1024$ & $1: 16$ & $1: 16$ \\
\hline Shepherd & $\mathrm{F}$ & 48 & - & & May 2009, family doctor & + & $1: 64$ & $1: 1024$ & $1: 16$ & $1: 16$ \\
\hline Shepherd & M & 22 & - & & September 2009 , family doctor & + & $1: 256$ & $1: 1024$ & $1: 16$ & $1: 16$ \\
\hline Shepherd & M & 45 & $+10 / 2008$ & - & May 2009 , family doctor & + & $1: 1024 *$ & $1: 1024$ & $1: 16$ & $1: 16$ \\
\hline Shepherd & $\mathrm{F}$ & 33 & - & & April 2009 , family doctor & + & $1: 256$ & $1: 512$ & $1: 16$ & $1: 16$ \\
\hline
\end{tabular}

AT, Antibiotic treatment; +, positive; -, negative; M, male; F, female.

* Possible chronic manifestation. 
shedding routes by ewes and through milk and vaginal mucus by goats, although the small numbers of samples mean that statistical analysis was not possible. Goats showed a considerably higher seroprevalence compared to sheep. The different seroprevalences may not be a result of different susceptibility to the infection as we did not know the precise time of entry of C. burnetii onto the farm or the route of transmission. Nonetheless, it is assumed that goats showed more clinical signs than sheep and that goats appeared more susceptible to $C$. burnetii infection.

The PCR results from blood samples showed a slightly higher infection rate in goats. This difference may not have been as a result of susceptibility to the infection, but might be related to the date of onset of the infection in the goat herd. The PCR results of the other shedding routes did not show any significant distinctions.

In human serum samples, Fournier \& Raoult [26] as well as Schneeberger et al. [27] showed that DNA of C. burnetii can be detected up to 17 days after onset of the disease. Similarly, Rolain \& Raoult [28] found DNA of C. burnetii in blood samples of patients with active $\mathrm{Q}$ fever. Marmion et al. [29] detected C. burnetii DNA in peripheral blood mononuclear cells (PBMC) and bone marrow until up to 12 years after an acute Q fever infection in humans, but only in cases of chronic fatigue syndrome. As C. burnetii infects monocytes/macrophages [2] bacterial DNA may remain detectable until these cells are renewed. Therefore it can be expected that PCR positivity of EDTA blood samples may be detected for longer as EDTA contains cellular components. The detection of $C$. burnetii DNA in serum or EDTA blood samples in humans suggests either a recent infection or chronic infection (e.g. endocarditis). The $3 \%$ of sheep and $8 \%$ of goats that were PCR positive in blood is consistent with a recent infection in this situation. A follow-up study should be performed to elucidate whether the animals have an acute infection or chronic Q fever. To the best of our knowledge, this is the first report on the detection of C. burnetii in blood samples of infected animals.

Unfortunately, due to organizational problems and legal reasons, the blood samples of the residents, the stockmen, and the plant breeders were taken 14 months after the first sampling of the sheep and goats. Only the stockmen and five of the farm residents had visited their family doctor prior to this, when $\mathrm{Q}$ fever was diagnosed. Two adult residents with clinical symptoms received antibiotic treatment (adult 1: penicillin and doxycycline each for 10 days; adult 2: doxycycline for 10 days). Remarkably, three children (aged 4, 11, 15 years) showed an increased antibody activity against $C$. burnetii in our investigations in July 2010. Nonetheless, only in the case of the 4-yearold child was the family doctor consulted during the acute infection, the child received antibiotic treatment against Q fever (erythromycin for the first 10 days, after no improvement ciprofloxacin for a further 10 days). The other two children did not notice any clinical signs or associate them with Q fever, which indicates seroconversion only. These individuals only became aware of their serological status because of our investigations in July 2010. The children reported that they had been in the stables frequently to stroke the lambs and watch the births during the lambing period. Even if the samples of the animals and the humans were not taken at the same time, the temporal relationship between the infections of the different host species suggests transmission between species.

The immediate vicinity of the dwellings, the office buildings and the stables (Fig. 1) explains why people living or working on the farm or its immediate surroundings were exposed to a high risk of infection. It is likely that most of the people with a positive antibody titre contracted the disease during the lambing period in spring 2009 whether they were symptomatic or not.

The titres (Table 2) were also consistent with the assumption that the infections took place some time previously and therefore probably at the time of lambing. IgM antibodies appear within 7 days on average and the $\mathrm{IgG}$ antibodies about 14 days after the onset of the acute infection [30]. IgM antibodies reach their maximum levels after 4-8 weeks and then decrease gradually over the following 10-12 weeks [31], and in some cases up to 17 weeks [32]. At least 4-6 months after the acute infection, as in this study, the antibodies will normally have disappeared or be present only at low levels [33, 34]. IgG antibodies against phase I and phase II antigen generally decrease gradually after 4-6 months, but phase II IgG antibodies can persist at a low titre (about 1:64 to $1: 1024)$ over several years [34]. The titres in this study are consistent with this pattern in that the IgM antibodies were at a low level or negative and the phase II IgG antibodies were elevated at a level between 1:64 and 1:1024 in all cases except one (50-year-old male resident) (Table 2). We expect that the $\mathrm{IgG}$ antibodies against phase I antigen will decrease. The male shepherd (45 years, with phase I IgG antibodies of 
$1: 1024)$ remains under serological follow-up because of the risk of chronic infection with $\mathrm{IgG}$ antibodies against a phase I IgG antigen of 1:1024 and persistently high phase II IgG antibodies [33]. It is not known whether he showed any clinical symptoms of chronic infection at the time of sampling. While we expect that the titres in these individuals represent recent infection it is possible that some of the positive results reflect past exposure particularly as the occupations of the individuals tested would put them at high risk of previous infection.

If we accept that all the seropositive individuals acquired their infection during this outbreak then $2 / 3$ people in the farm village were infected during or just after the lambing period. This high rate of positivity would be consistent with the close contact between humans and animals in this village and with the rather long exposure time generated through shedding during three lambing periods [two lambing periods in sheep and one in goats (Fig. 2)].

The rate of infected humans with clinical symptoms compared to those who were seropositive without any clinical signs within the time of exposure was $1: 2 \cdot 2$. The ratio of symptomatic or asymptomatic reported cases to non-reported cases was $1: 1 \cdot 6$. This contrasts with $\mathrm{Q}$ fever outbreaks described previously where the relationship between reported cases and non-reported cases without or with only mild clinical symptoms was 1:3.5 (S. F. Fischer, unpublished data). A possible reason for this might be the awareness of $\mathrm{Q}$ fever by the people living or working at the farm in question and therefore an awareness of Q fever by their family doctors.

We propose that Q fever infection was introduced into the herd by a trainee stockman and his sheepdog, who were at Upper Lindenhof for an apprenticeship from the beginning of 2008 until April 2009 (Fig. 2). We suspect the $C$. burnetii infection was carried from the parental farm (where Q fever was known to be present in spring 2008) to Upper Lindenhof. Unfortunately as we were unable to obtain any samples from the trainee and his dog this hypothesis could not be confirmed.

The temporal relationship makes us suspect that they were possible vectors for the bacteria carrying it from one farm to the other, e.g. in the dog's coat or in the trainee's working clothes. As one of the stockmen became ill in December 2008 it can be speculated that Q fever had already been on the farm at the end of 2008. At that time the infection in the flock was probably disregarded, because the human patient was not checked for Q fever until May 2009 and there was no lambing period in the sheep and goat flocks. Thus, the typical clinical signs such as abortion, stillbirth and the delivery of weak offspring did not occur in the flocks. Other obvious clinical signs in the nonlambing period were not established, so possible infected animals could not be observed.

Nevertheless, retrospectively it is impossible to be certain through which route the bacteria were transmitted to the farm. Infection through introduction of new stock can be ruled out in this case, because only rams were purchased, but their serological and PCR results (blood, faecal, prepuce swabs) were negative in the tests in summer 2009. Finally four possible options of introduction remained:

(1) The theory concerning the trainee stockman, since the stockman's illness in December 2008 was Q fever. We believe that this is the most likely route of transmission.

(2) The possibility that shepherds, who attended the sheep-shearing workshop at the end of January 2009, transmitted C. burnetii to the flock via their work clothes, instruments or vehicles.

(3) The possibility that other animal species, e.g. pigs, cattle, and poultry kept in the valley section of the research station might already be infected. Some of the employees were in contact with both sections and all animals and machinery. Unfortunately, it was not possible to sample the animals at Lower Lindenhof, so we cannot rule out this infection route.

(4) The possibility of transmission by wildlife or rodents cannot be excluded, especially because we were unable to sample any of them.

However, these are only four known routes as to how C. burnetii could have been transmitted to this farm and several other unknown routes could also be possible.

No clinical Q fever infections, either in humans or in other host species, were notified at Lower Lindenhof and in the surrounding villages at the time of the outbreak. The isolated site of Upper Lindenhof and the fact that the farm was enclosed by forest on three sides, thus restricting the windborne spread of C. burnetii [35], probably explains the localized nature of the outbreak.

These investigations were the beginning of a series of experiments which took place at Upper Lindenhof at the Research Station for Animal Husbandry, Animal Breeding and Small Animal 
Breeding, University of Hohenheim. It is hoped that further investigations will enhance our understanding of the pathogenesis, the epidemiology and a possible treatment of Q fever in small ruminants in order to reduce or even avoid human infections.

\section{ACKNOWLEDGEMENTS}

The investigation was funded by the Federal Ministry of Education and Research, Germany, Grant 01KI0734. We thank CVUA Fellbach for providing the results of their investigations in April 2009. Moreover, we are grateful for the investigations performed and the support given by the Research Station for Animal Husbandry, Animal Breeding and Small Animal Breeding, University of Hohenheim and its employees. Furthermore, we thank Frances Sherwood-Brock for reading the English manuscript. The authors also thank Ingola von Keyserlingk, Sabine Baumann, Sandra Schöbel, Marie Hasselmann (LAVES), and Malte Diederichsen (Clinic for Swine and Small Ruminants) for their excellent laboratory technical assistance.

\section{DECLARATION OF INTEREST}

None

\section{REFERENCES}

1. Rodolakis A. Q fever, state of art: epidemiology, diagnosis and prophylaxis. Small Ruminant Research 2006; 62: 121-124.

2. Angelakis E, Raoult D. Q fever. Veterinary Microbiology 2010; 140: 297-309.

3. Raoult D, Marrie TJ, Mege JL. Natural history and pathophysiology of Q fever. Lancet Infectious Disease 2005; 5: 219-226.

4. Arricau-Bouvery N, Rodolakis A. Is Q fever an emerging or re-emerging zoonosis? Veterinary Research 2005 ; 36: 327-349.

5. Heinzen RA, Hackstadt T, Samuel JE. Developmental biology of Coxiella burnetii. Trends in Microbiology 1999; 7: 149-154.

6. Welsh HH, et al. Air-borne transmission of Q feverthe role of parturition in the generation of infective aerosols. Annals of the New York Academy of Science 1958; 70: 528-540.

7. Porten K, et al. A super-spreading ewe infects hundreds with $\mathrm{Q}$ fever at a farmers' market in Germany. $B M C$ Infectious Disease 2006; 6: 13.

8. Wiebe ME, Shankel DM, Burton PR. Isolation and characterization of 2 cell types of Coxiella burnetii phase I. Journal of Bacteriology 1972; 110: 368-377.
9. Woldehiwet Z. Q fever (coxiellosis): epidemiology and pathogenesis. Research in Veterinary Science 2004; 77 : 93-100.

10. Stoker MGP, Fiset $P$. Phase variation of the 9 mile and other strains of Rickettsia burnetii. Canadian Journal of Microbiology 1956; 2: 310-321.

11. Runge M, Ganter M. Q fever. Journal of Consumer Protection and Food Safety 2008; 3: 185-189.

12. Maurin M, Raoult D. Q fever. Clinical Microbiology Review 1999; 12: 518-553.

13. Berri M, Laroucau K, Rodolakis A. The detection of Coxiella burnetii from ovine genital swabs, milk and fecal samples by the use of a single touchdown polymerase chain reaction. Veterinary Microbiology 2000; 72: 285-293.

14. Baca OG, Paretsky D. Q fever and Coxiella burnetii - a model for host-parasite interactions. Microbiological Reviews 1983; 47: 127-149.

15. Tissot-Dupont H, Raoult D. Epidemiology of Q fever [in French]. Bulletin Épidémiologique Hebdomadaire 1993; 5: 17-18.

16. Palmer NC, et al. Placentitis and abortion in goats and sheep in Ontario caused by Coxiella burnetii. Canadian Veterinary Journal 1983; 24: 60-61.

17. Berri M, et al. Relationships between the shedding of Coxiella burnetii, clinical signs and serological responses of 34 sheep. Veterinary Record 2001; 148: $502-505$.

18. Abinanti FR, et al. Q fever studies.18. Presence of Coxiella burnetii in the birth fluids of naturally infected sheep. American Journal of Hygiene 1953; 58: 385-388.

19. Arricau-Bouvery NA, et al. Experimental Coxiella burnetii infection in pregnant goats: excretion routes. Veterinary Research 2003; 34: 423-433.

20. Fishbein DB, Raoult D. A cluster of Coxiella burnetii infections associated with exposure to vaccinated goats and their unpasteurized dairy products. American Journal of Tropical Medicine and Hygiene 1992; 47 : $35-40$.

21. Fournier PE, Marrie TJ, Raoult D. Diagnosis of Q fever. Journal of Clinical Microbiology 1998; 36: 1823 1834.

22. Ganter M, Herrmann J, Waibl H. Blood sampling from the vena cava cranialis in sheep and goat using sampling systems armed by canula. Tierarztliche Praxis Ausgabe Großtiere Nutztiere 2001 ; 29: 37-40.

23. Willems $\mathbf{H}$, et al. Detection of Coxiella burnetii in cows milk using the polymerase chain-reaction (PCR). Journal of Veterinary Medicine Series B: Infectious Disease and Veterinary Public Health 1994; 41 : 580-587.

24. Hatchette TF, et al. Goat-associated Q fever: a new disease in Newfoundland. Emerging Infectious Disease 2001; 7 : 413-419.

25. Astobiza I, et al. Kinetics of Coxiella burnetii excretion in a commercial dairy sheep flock after treatment with oxytetracycline. Veterinary Journal 2010; 184: 172-175.

26. Fournier PE, Raoult D. Comparison of PCR and serology assays for early diagnosis of acute Q fever. Journal of Clinical Microbiology 2003; 41 : 5094-5098. 
27. Schneeberger PM, et al. Real-time PCR with serum samples is indispensable for early diagnosis of acute Q fever. Clinical and Vaccine Immunology 2010; 17: 286-290.

28. Rolain JM, Raoult D. Molecular detection of Coxiella burnetii in blood and sera during $\mathrm{Q}$ fever. QJM. An International Journal of Medicine 2005; 98: 615-617.

29. Marmion BP, et al. Long-term persistence of Coxiella burnetii after acute primary $\mathrm{Q}$ fever. QJM : An International Journal of Medicine 2005; 98: 7-20.

30. Guigno D, et al. Primary humoral antibody-response to Coxiella burnetii, the causative agent of Q fever. Journal of Clinical Microbiology 1992; 30: 1958-1967.

31. Dupuis G, et al. Immunoglobulin responses in acute Q-fever. Journal of Clinical Microbiology 1985; 22: 484-487.
32. Hunt JG, Field PR, Murphy AM. Immunoglobulin responses to Coxiella burnetii ( $\mathrm{Q}$ fever) - single-serum diagnosis of acute infection, using an immunofluorescence technique. Infection and Immunity 1983; 39: 977-981.

33. Wagner-Wiening C, Brockmann S, Kimmig P. Serological diagnosis and follow-up of asymptomatic and acute Q fever infections. International Journal of Medical Microbiology 2006; 296: 294-296.

34. Kimmig P, Wagner-Wiening C. Coxiella burnetii. In: Neumeister B, et al., eds. Mikrobiologische Diagnostik. Germany/USA: Stuttgart/New York, 2009, pp. 628632.

35. Tissot-Dupont H, et al. Wind in November, Q fever in December. Emerging Infectious Disease 2004; 10: 1264-1269. 